\title{
"We have to turn ourselves into soldiers, ready to fight": War Frames in the South African State's Response to COVID-19
}

\author{
Gabriela Pinheiro \\ Centre for Sexualities, AIDS and Gender (University of Pretoria, South Africa)
}

\begin{abstract}
War metaphors and biomilitarism have achieved considerable primacy in the framing and management of infectious disease outbreaks. During the COVID-19 pandemic, South African state response has relied heavily on militarisation and warring to 'defeat' an anthropomorphised 'invisible enemy'. Discursive frames reflect, but also inform, social configurations and people's lived realities. In times of crisis, frames can be used to mobilise action and resources, and even to galvanise collective feelings on behalf of particular social actors. Frames are not neutral, but profoundly imbricated in the (re)production of prevailing social and structural power imbalances. In this paper, South Africa's "War on COVID" is problematised. A Critical Discourse Analysis of national addresses to the South African public foregrounds how the warring of COVID-19 conceals structural inequalities and re/inscribes social divisions. I argue that 'warring' the pandemic engages historicallyinformed systems of racism and classism that disenfranchise and devalue poor, black South African people in particular. The deaths of Collins Khosa and Nathanial Julius alert us to the ways in which militarisation and warring are implicated in racist and classist politics and practices. In South Africa, such practices stem from historical-political and social influences that are inherently anti-black. The analysis foregrounds how the ethics of framing are replete with questions of personhood, legitimate citizenry, in/valid living and the grievability of particular bodies. Ultimately, it is argued that "turning ourselves into soldiers" can no longer be considered a viable means to tackle humanitarian and health crises, for it is largely incompatible with meaningful transformation and equal citizenship.
\end{abstract}

Keywords: pandemic; biomilitarism; discursive frames; war metaphors; identity politics 